\title{
Establishment of transition point in operating mode for Constant Current Constant Voltage (CC-CV) charging of Li-ion batteries
}

\author{
Amit Kumar De ${ }^{1,{ }^{*}}$ and Shobhana Dey ${ }^{2}$ \\ ${ }^{1}$ Electrical and Electronics Engineering, Birla Institute of Technology, Mesra, Ranchi, India. \\ ${ }^{2}$ Mineral Processing Division, CSIR-National Metallurgical Laboratory, India.
}

World Journal of Advanced Engineering Technology and Sciences, 2021, 03(01), 072-083

Publication history: Received on 23 June 2021; revised on 22 August 2021; accepted on 24 August 2021

Article DOI: https://doi.org/10.30574/wjaets.2021.3.1.0053

\begin{abstract}
The present-day Li-ion batteries when operated, needs precise monitoring of the charging voltage. Several charging techniques have been tested so far with varying degrees of success. One of the most widely used charging techniques is the CC-CV (constant current constant voltage) charging. When performing this, the safety considerations must be maintained with respect to over voltage charging which is a very common problem during constant current charging. In order to prevent over voltage charging, the charging mode must be then shifted from CC to CV mode. So, this transition point of the charging mode from CC to CV is very crucial for the safe operation and health of the battery in the long run. The problem is that, this transition point doesn't remain the same for the battery. So, in this paper the factors on which it depends are discussed and a Li-ion battery was charged in a few different charging rates using the CC-CV technique to demonstrate the process.
\end{abstract}

Keywords: Constant current charging; Constant voltage charging; SoC estimation; Battery safety; Charging rate

\section{Introduction}

The present-day technologies regarding Lithium-ion batteries have enabled them to find greater applications in our daily lives. As it grows in size with respect to its user base, more and more shortcomings of the technology used to handle them, crops up. This is evident from the multiple reports of Lithium-ion battery explosions in cell phones etc, which highlight the need for a safer battery charging system. If a small battery of the order of around 2 to $5 \mathrm{Ah}$ used in cell phones can cause such havoc then it is not hard to imagine how bad the situation could be, if things go wrong in a charging station with battery banks that are thousands of times the capacity of the former [1,2, 3]. Lithium-ion batteries as we know are very sensitive to the charging voltage and current $[4,5]$. It needs to be monitored both during charging as well discharging. During charging, as the battery voltage gradually goes up, the charging voltage should not exceed $4.2 \mathrm{~V}$ for prolonged periods of time in case of a standard Lithium-ion battery $[5,6]$.

In order to achieve the said protections, one of the most common modes of charging used, is the Constant current Constant voltage mode of charging [7, 8]. In this method, the cell is charged at a constant current until a certain voltage is reached and beyond that voltage, the mode is switched to constant voltage and so the charging current value gradually decreases. Some reports call this constant voltage method of charging as trickle charging. This step is a very important factor as it not only prevents the charging voltage from exceeding the $4.2 \mathrm{~V}$ but also ensures an unforced charging of the battery according to its chemical state internally. This natural charging at constant voltage helps to maintain the battery health as well [9].

\footnotetext{
${ }^{*}$ Corresponding author: Amit Kumar De

Electrical and Electronics Engineering, Birla Institute of Technology, Mesra, Ranchi, India.
} 
So, it is important to have an idea about the point of transition in the charging mode when designing a charger. This point of transition is however not as simple to determine as it depends on a few factors. But it is important to set a reference to gauge the transition i.e., whether to measure it in reference to a certain voltage or State of Charge of the battery. It is easier to just set the transition point to a battery voltage of $4.2 \mathrm{~V}$ while it is being charged. However, this is where the first factor demonstrates its importance. The first factor is the charging rate. A simple equation to demonstrate the reason behind that is given in the studies of [10]. Simply put, the higher the rate of charging, the earlier the transition state is reached.

The next important factor that determines the transition voltage of $4.2 \mathrm{~V}$ is the age of the cell or the number of charge cycles that the cell has experienced. An average lithium-ion cell can have a charge cycle ranging from 100 to 1000 [11, $12,13]$. When dealing with lithium-ion batteries, the end of charge voltage is around 4.2V [14]. But experimental results have shown that as the number of charge cycles increase, the end of charge voltage slowly decrease. So, in case of an old battery if we are trying to charge it with an end of charge voltage of $4.2 \mathrm{~V}$ then we are actually over charging it as even at $100 \%$ capacity, they might have a voltage of only $3.8 \mathrm{~V}$ to $3.9 \mathrm{~V}$. Hence this type of overcharging even when the end of charge voltage is set to $4.2 \mathrm{~V}$ is a common mistake that is overlooked in many cases.

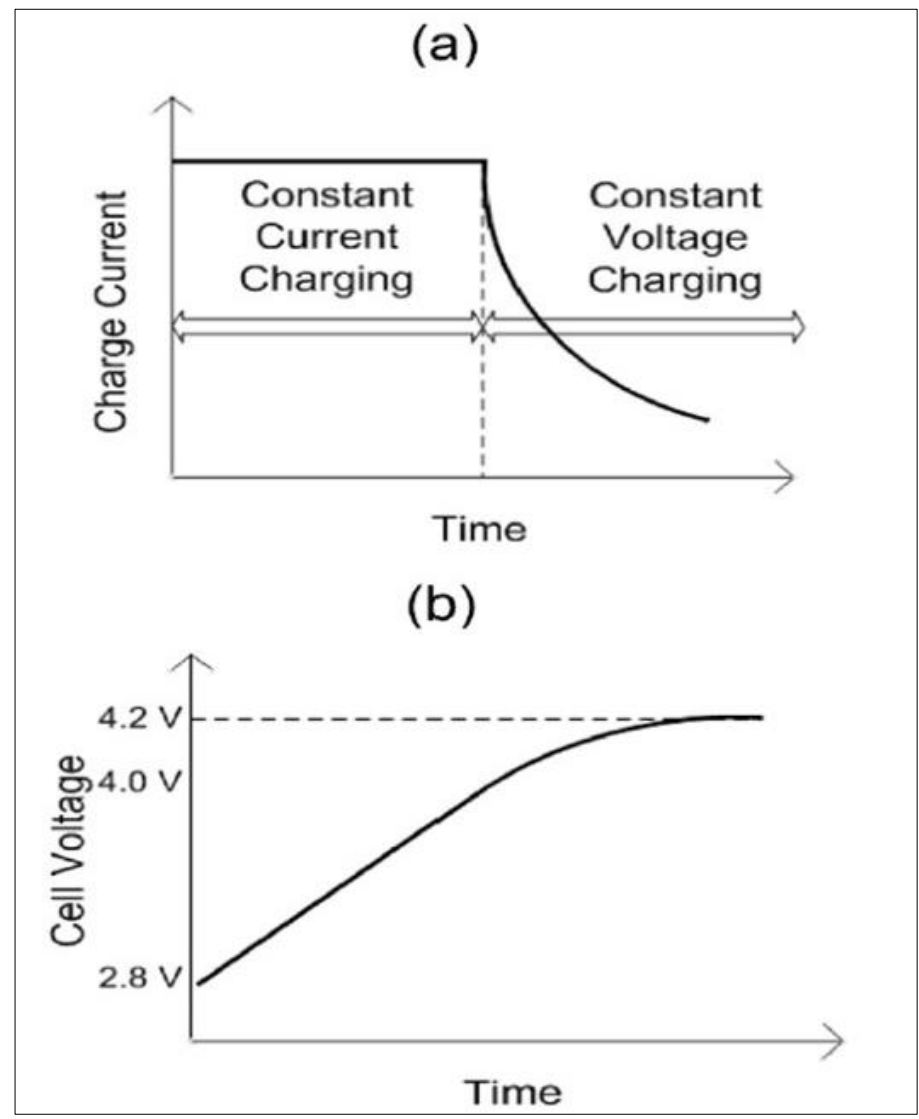

Figure 1 a) Typical CC-CV Charging Current Profile of a Li-ion Cell. b) Typical Cell Voltage Increase of a Li-ion cell. [ After: [15]]

The final factor is the capacity of the battery as it enables the battery to be charged at a higher rate. This paper however will be focusing on the effects of the charging rate only.

The battery parameters that were monitored for this process were the battery voltage and the charging current. Figure 1.a \& 1.b shows a typical Li-ion current and voltage profiles respectively [15]. The plots that were made from logging the battery parameters were compared with the standard curves for CC-CV charging process.

Other notable trend from the experiments conducted when the CC-CV charging was performed at different charging rates, was the difference in the amount of charge transferred to the battery. 


\section{Methodology}

The aim of the study was to observe the rate of drop in charging current after the safety limit of $4.2 \mathrm{~V}$ was reached. But the important factor is that, as the battery ages, the end of charge voltage or the safety voltage as is defined by many manufactures may not be maintained. It slowly drops over time and so the point of transition from CC to CV charging also need to shift accordingly. This experiment was conducted on a Li-ion battery of capacity $2000 \mathrm{mAh}$ with barely 2 charge cycles. The battery was subjected to 3 different rates of charging and they were discharged to a discharge cutoff voltage of $3.21 \mathrm{~V}$ as beyond $3.2 \mathrm{~V}$ the battery might be chemically unstable and its lifetime might be negatively affected $[11,12,13]$. Then the SoC was calculated by coulomb counting method using the equations 2 and 3 and the change in the point of mode transition was then noted for different charge rates.

\subsection{Software Tools and components used}

This method requires a DC current sensor as well as a Voltage sensor to measure the analog values and were then sent to the micro-controller where they were then processed via its ADC inputs. As for the main charging circuit, a simple DC-DC buck converter was designed which was operated at 35kHz. The Micro-controller used was an Arduino Mega 2560.

The components used in the buck converter were as follows:

MOSFET: IRF540N

Optocoupler for driver circuit: HCPL-0302-000E

Inductor: $330 \mathrm{uH}, 5.2 \mathrm{~A}$ max current, toroidal

Ultra-fast recovery diode: MUR860

Power supply for driver: standard 9V battery

Power supply for the battery charger: $230 \mathrm{~V}$ to $12 \mathrm{~V}$ output transformer, $220 \mathrm{uF} 40 \mathrm{~V}$ electrolytic capacitor (for input to voltage regulator), $47 \mathrm{uF} 25 \mathrm{~V}$ electrolytic capacitor (output side), LM7812 voltage regulator, KBP210 bridge diode.

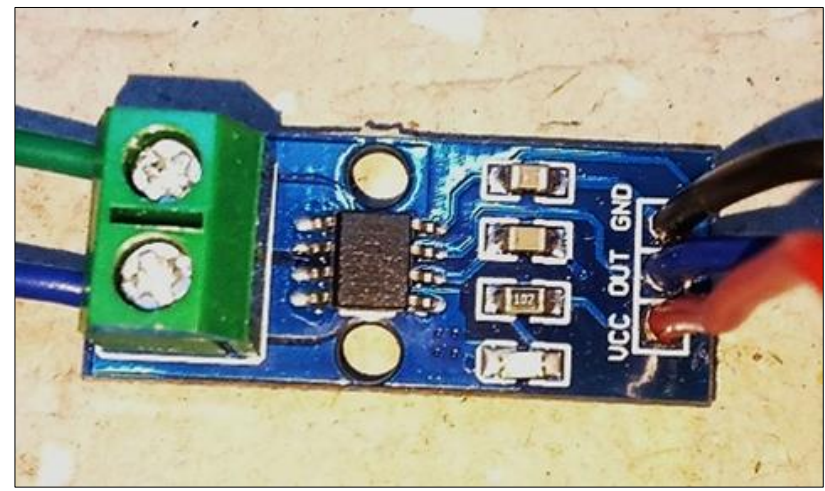

Figure 2 The ACS 712 sensor

The current sensor used was ACS 712 which is a hall effect sensor with a sensing range of 0 to $5 \mathrm{~A}$. The voltage sensor is basically a potential divider with two precision resistors of $30 \mathrm{k} \mathrm{ohm}$ and $7.5 \mathrm{k} \mathrm{ohm} \mathrm{(1 \%} \mathrm{tolerance} \mathrm{for} \mathrm{both)} \mathrm{in} \mathrm{which} \mathrm{the}$ output is taken against the $7.5 \mathrm{k} \mathrm{ohm}$ resistor. It has a sensing range of 0 to $25 \mathrm{~V}$.

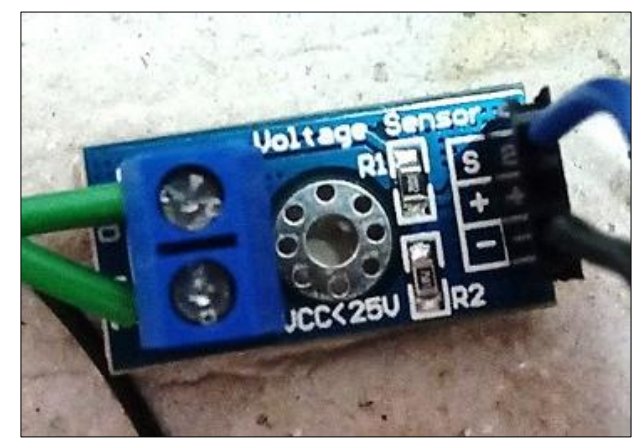

Figure 3 The Voltage sensor used in the experiments 
The battery used in the test is an ICR18650-20C Li-ion 3.7V battery with an age of about 2 or 3 charge cycles and rated at about $2000 \mathrm{mAh}$ capacity. The capacity however may not be exact and therefore it will be calculated in the tests later. The battery was rated at a maximum charging rate of $2 \mathrm{C}$ or 4 Amperes in this case.

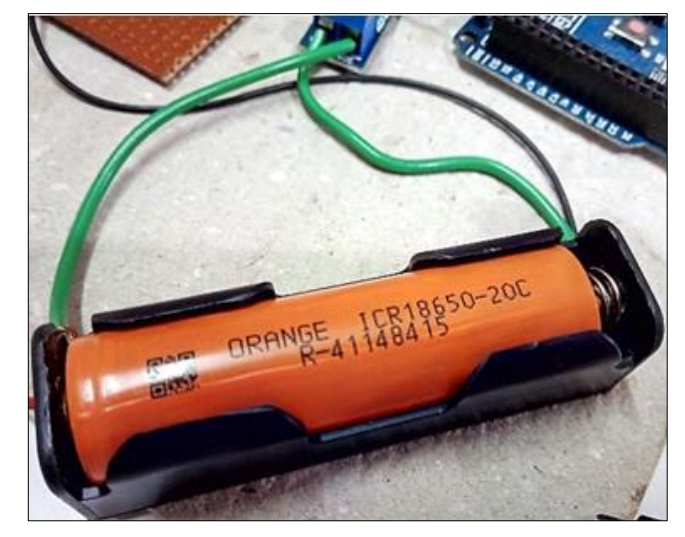

Figure 4 The 2000mAh 18650 battery used

The different software used were Arduino IDE (for the micro-controller programming) and TeraTerm (for logging the data from Arduino to Excel via serial communication).

The multi-meter used to measure and calibrate the sensors was a MECO 108B+ TRMS.

\subsection{Charging process}

In order to achieve CC CV charging, initially the system was started with a fixed reference current that was defined based on the capacity of battery that needed to be charged. The duty cycle of the converter was gradually increased in steps and then the output was continuously checked against the reference current value.

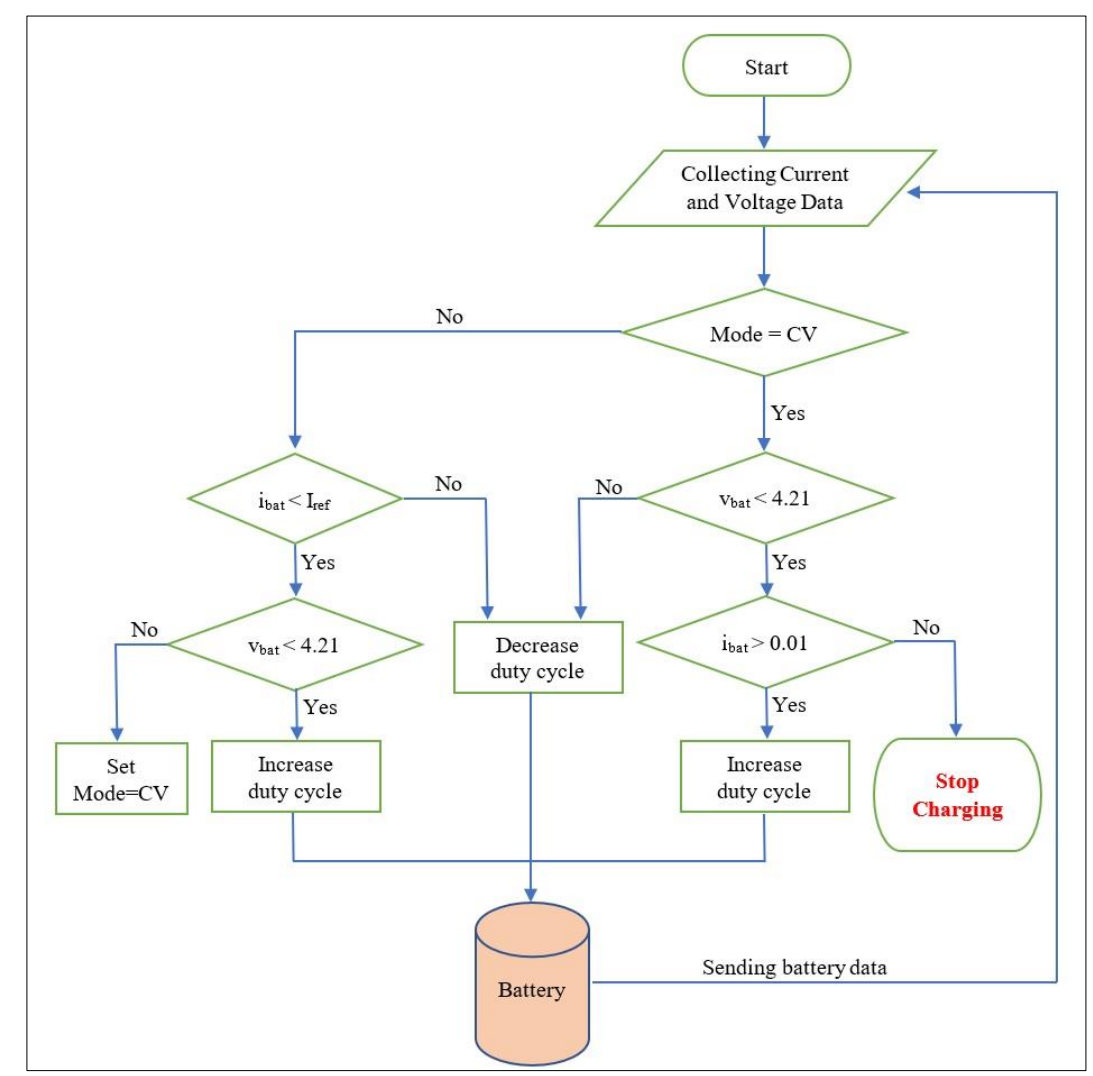

Figure 5 Charging algorithm explained by a flowchart 
When the output current exceeded the reference current, the duty cycle was reduced slightly to compensate for the slight overshoot and thus maintained a constant output current. At the same time, the battery voltage was also measured and monitored so that it didn't exceed the maximum charging voltage of $4.2 \mathrm{~V}$. Some battery manufactures mention a tolerance of $\pm 0.05 \mathrm{~V}$ in the charging voltage. Therefore, effectively the charging can be done up to voltages of $4.25 \mathrm{~V}$ but in the experiments conducted for this study, the maximum charging voltage was restricted to $4.21 \mathrm{~V}$ so that the end of charge voltage of the battery was $4.2 \mathrm{~V}$ or slightly below it.

The transitions were defined by a consistency factor in the program for the control of the system via the micro controller. This consistency factor was set to 10 which means it checked if the sensor readings met the conditions for a transition for 10 consecutive seconds without fail. If that check was completed, only then would the transition in mode or the termination of the charging process would trigger. The importance of the consistency factor is that it helps to eliminate errors of early or pre-mature transition due to noise.

However, the value of the consistency factor was much higher for the point at which the charging process would terminate. This was because when the charging process is almost complete, the battery draws very little current and is trickle charged. Hence, it needs to be checked for a much longer time as the changes are very slow during this process and the battery draws very little power in the order of less than $100 \mathrm{~mW}$. The precise conditions used to determine the transitions are as follows:

\subsubsection{Mode change from $\mathrm{CC}$ to $\mathrm{CV}$}

Process initially starts with CC charging mode and to change to CV charging mode, charging voltage must be at least $4.21 \mathrm{~V}$ consistently for more than 10 seconds.

\subsubsection{Determination of end of charging process}

The charging current must be less than or equal to $0.01 \mathrm{~A}$ or $10 \mathrm{~mA}$ consistently for 50 seconds or more and the charging process must be in CV mode.

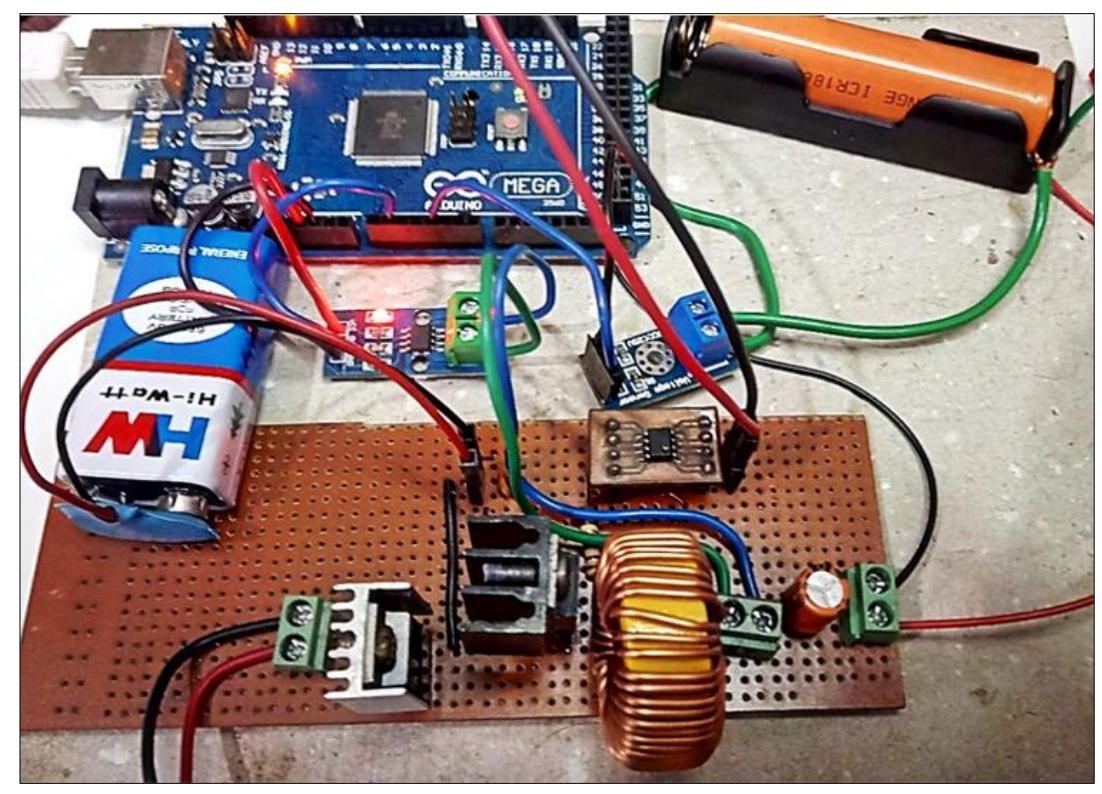

Figure 6 The buck converter setup for the charging process

To demonstrate the results of the study, several charge cycles of the battery were performed to validate the data consistency. The ICR18650 2000mAh battery was charged at 3 different charging rates of $0.85 \mathrm{~A}, 1.0 \mathrm{~A}$ and $1.5 \mathrm{~A}$ respectively. This was done in order to calculate the useable capacity of the battery. The total charge transferred was estimated using equation no 2 .

\subsection{Formulae used}

The experiments conducted here is mainly based on a few formulae. The first one is for the buck converter whose output was regulated during the charging process to maintain a constant current or a constant voltage depending on the mode. 


$$
V_{\text {out }}=D * V_{\text {in }}
$$

where,

$\mathrm{V}_{\text {out }}=$ battery charging voltage

$V_{\text {in }}=$ supply voltage

$\mathrm{D}=$ duty-cycle of the converter

The second equation is needed to estimate the capacity of the battery and then the State of Charge of the battery. Here the assumption is that at $n=0$, the current is 0 .

$$
Q_{\text {total }}=\sum_{n=1}^{T} i_{t} *\left(t_{n}-t_{n-1}\right)
$$

where,

$Q_{\text {total }}=$ total charge transferred (in Amp-sec)

$\mathrm{i}_{\mathrm{t}}=$ instantaneous charging current (in Amp)

$t_{n}=$ time of $n^{\text {th }}$ reading in seconds

$\mathrm{t}_{\mathrm{n}-1}=$ time of $(\mathrm{n}-1)^{\mathrm{th}}$ reading in seconds

$\mathrm{T}=$ total time of charging in seconds

Another formula used to calculate the State of charge of the battery (assuming SoC at $t=0$ is 0 ) is given by:

$$
(S o C)_{t}=\frac{\left\{\sum_{n=1}^{t}\left\{i_{t} *\left(t_{n}-t_{n-1}\right)\right\}\right\}}{Q_{\text {total }}} * 100 \%
$$

where,

$$
\begin{aligned}
& (\mathrm{SoC})_{\mathrm{t}}=\text { State of charge at any time " } \mathrm{t} \text { " } \\
& Q_{\text {total }}=\text { total charge transferred (in Amp-sec) } \\
& \mathrm{i}_{\mathrm{t}}=\text { instantaneous charging current (in Amp) } \\
& \mathrm{t}_{\mathrm{n}}=\text { time of } \mathrm{n}^{\text {th }} \text { reading in seconds } \\
& \mathrm{t}_{\mathrm{n}-1}=\text { time of }(\mathrm{n}-1)^{\text {th }} \text { reading in seconds }
\end{aligned}
$$

\section{Results and discussion}

The data collected from the experiments conducted shows that the rate of charge has a significant impact on the transition point of the charging mode as well as in the total amount of charge transferred. After a few charge cycles for SoC calculation, it was found that the maximum battery capacity is about $2197 \mathrm{mAh}$. The End of discharge voltage for the battery was around 3.23V. Since, the battery may become chemically unstable when discharged beyond 3.2V [11], it was taken care that the discharge was stopped when the battery voltage reached 3.2V.

A value of $2197 \mathrm{mAh}$ was taken as the reference for maximum battery capacity after multiple tests in the hardware data logging setup which was designed as shown later. The SoC of the battery was then calculated at different times within the charging period.

It was then seen in figure 7 that the mode transition occurred at $97.7 \%$ SoC when the battery was charged at a current of $0.85 \mathrm{~A}$ during the CC mode. The charging process lasted for about 11,745 seconds or $3 \mathrm{hr} 15 \mathrm{mins}$. The battery was 
World Journal of Advanced Engineering Technology and Sciences, 2021, 03(01), 072-083

charged up to about $2197 \mathrm{mAh}$ during the process. The plots show that the nature of the curve is in accordance with the standard curves as in [15].

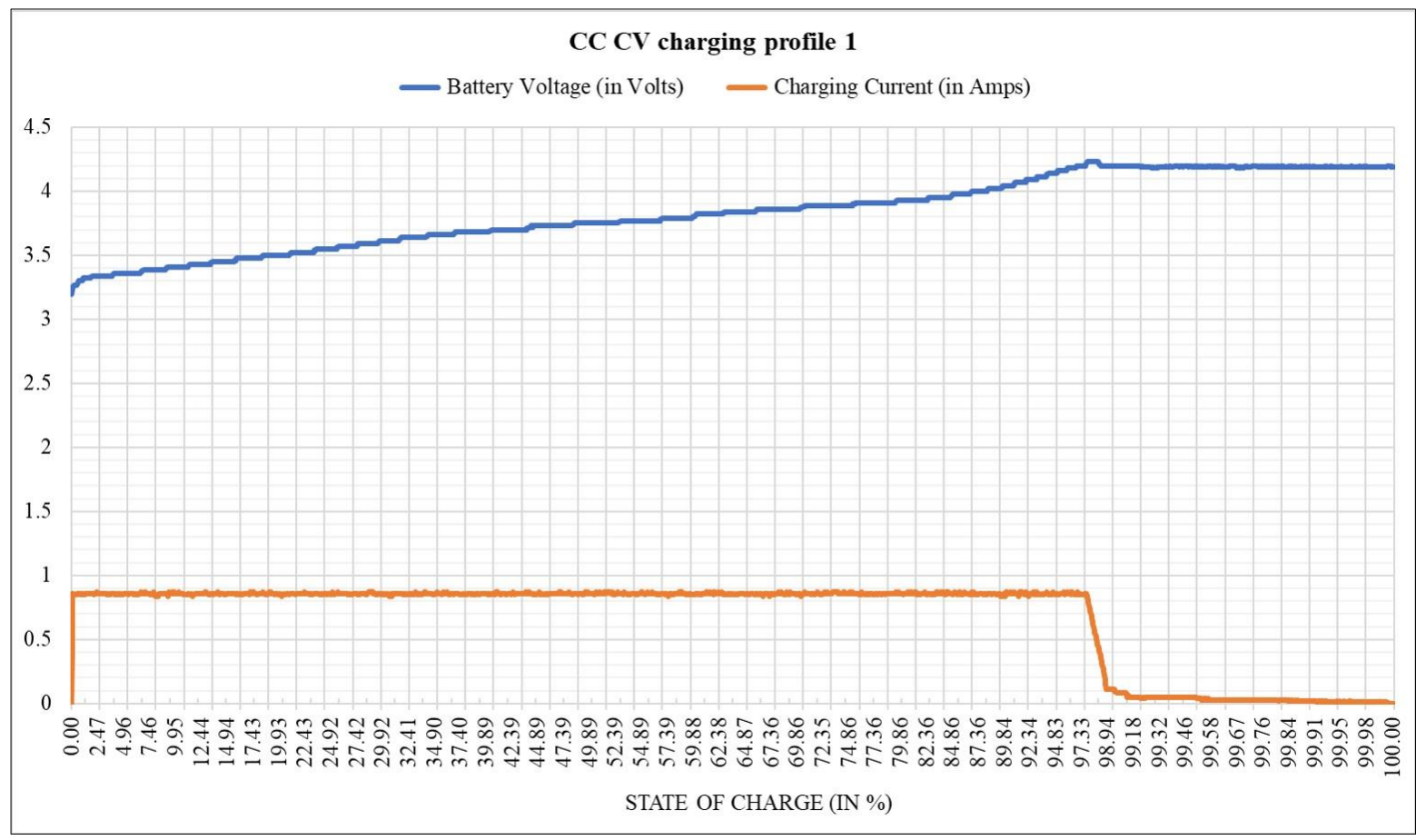

Figure 7 Charging profile with $0.85 \mathrm{~A}$ charging rate against SoC

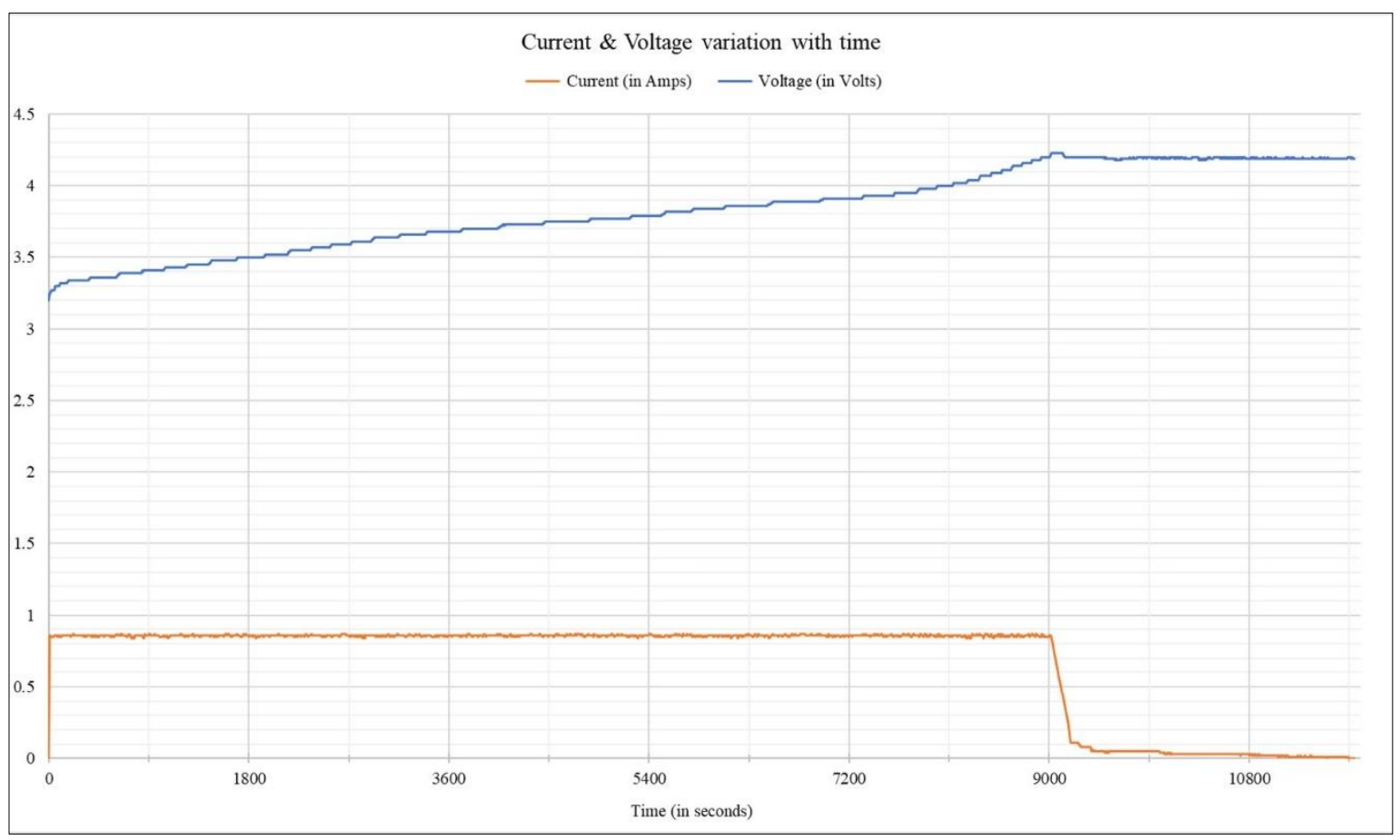

Figure 8 Charging profile with $0.85 \mathrm{~A}$ charging rate against time 
World Journal of Advanced Engineering Technology and Sciences, 2021, 03(01), 072-083

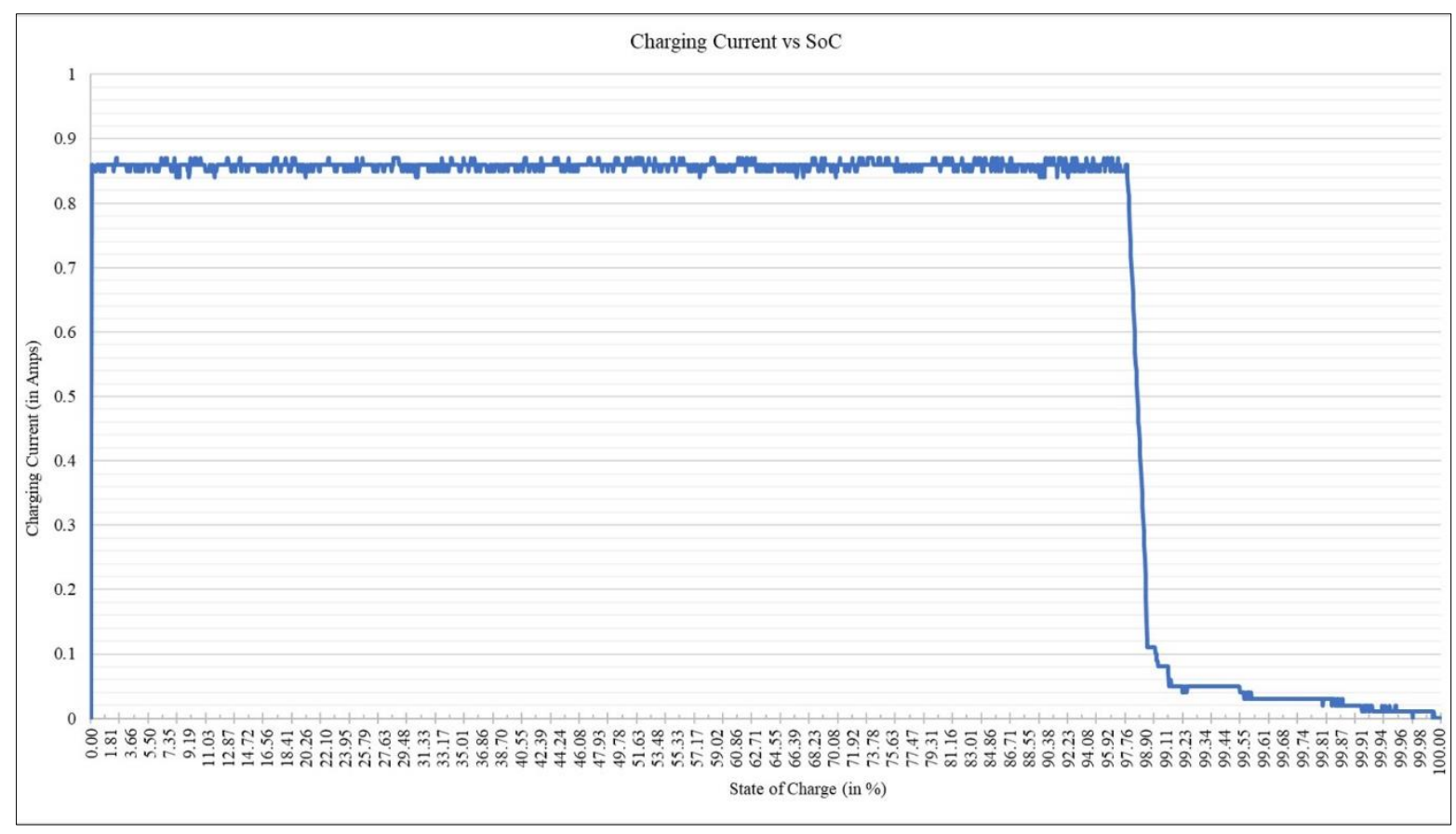

Figure 9 Current profile with $0.85 \mathrm{~A}$ charging rate

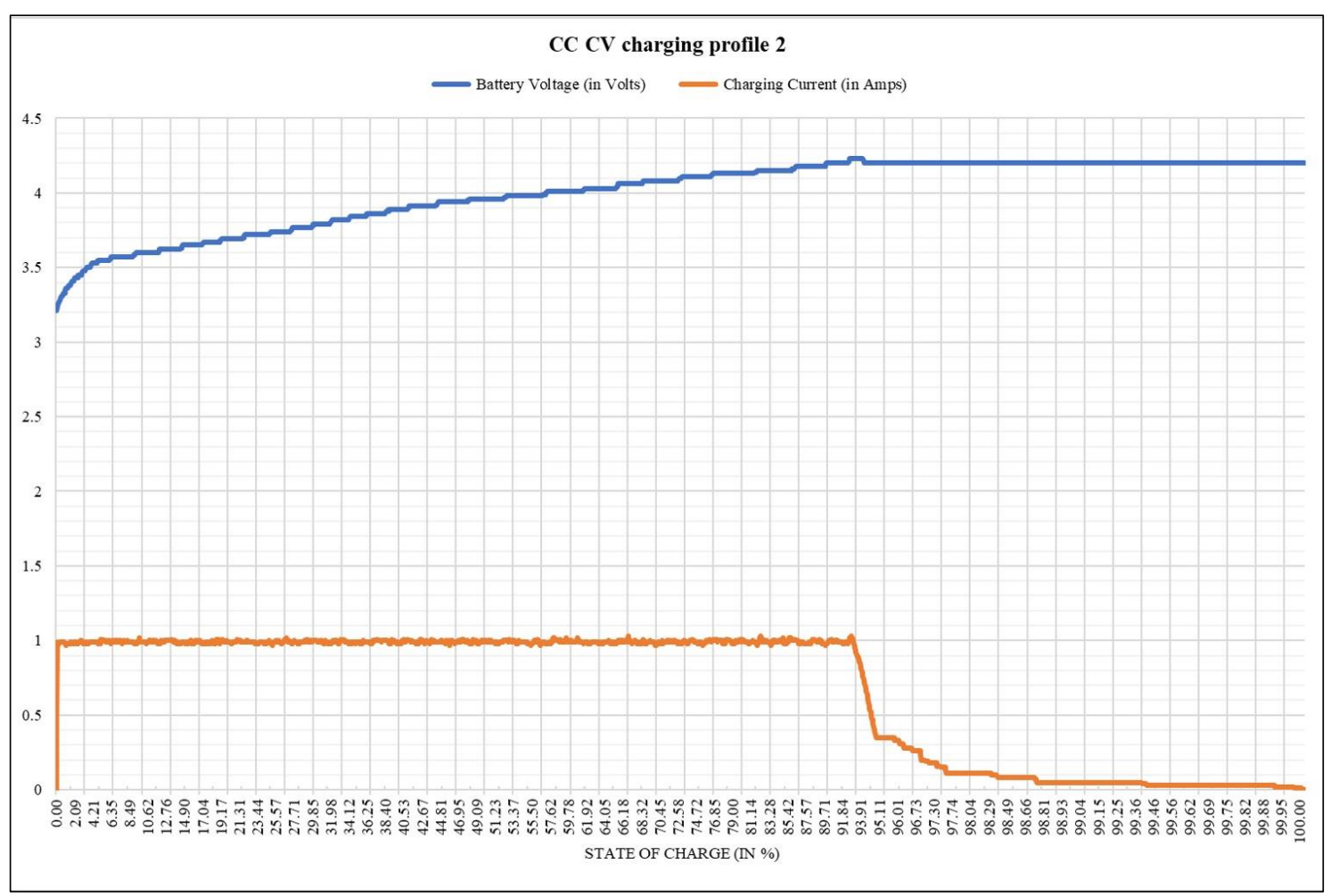

Figure 10 Charging profile with 1.0A charging rate

In case of the charge cycle in CC CV mode with a reference current of $1 \mathrm{~A}$ during the CC mode, the transition occurred at $92.64 \% \mathrm{SoC}$ when the battery was charged up to $2062 \mathrm{mAh}$. The total charging time was 10,925 seconds or $3 \mathrm{hrs} 2 \mathrm{mins}$. 
World Journal of Advanced Engineering Technology and Sciences, 2021, 03(01), 072-083

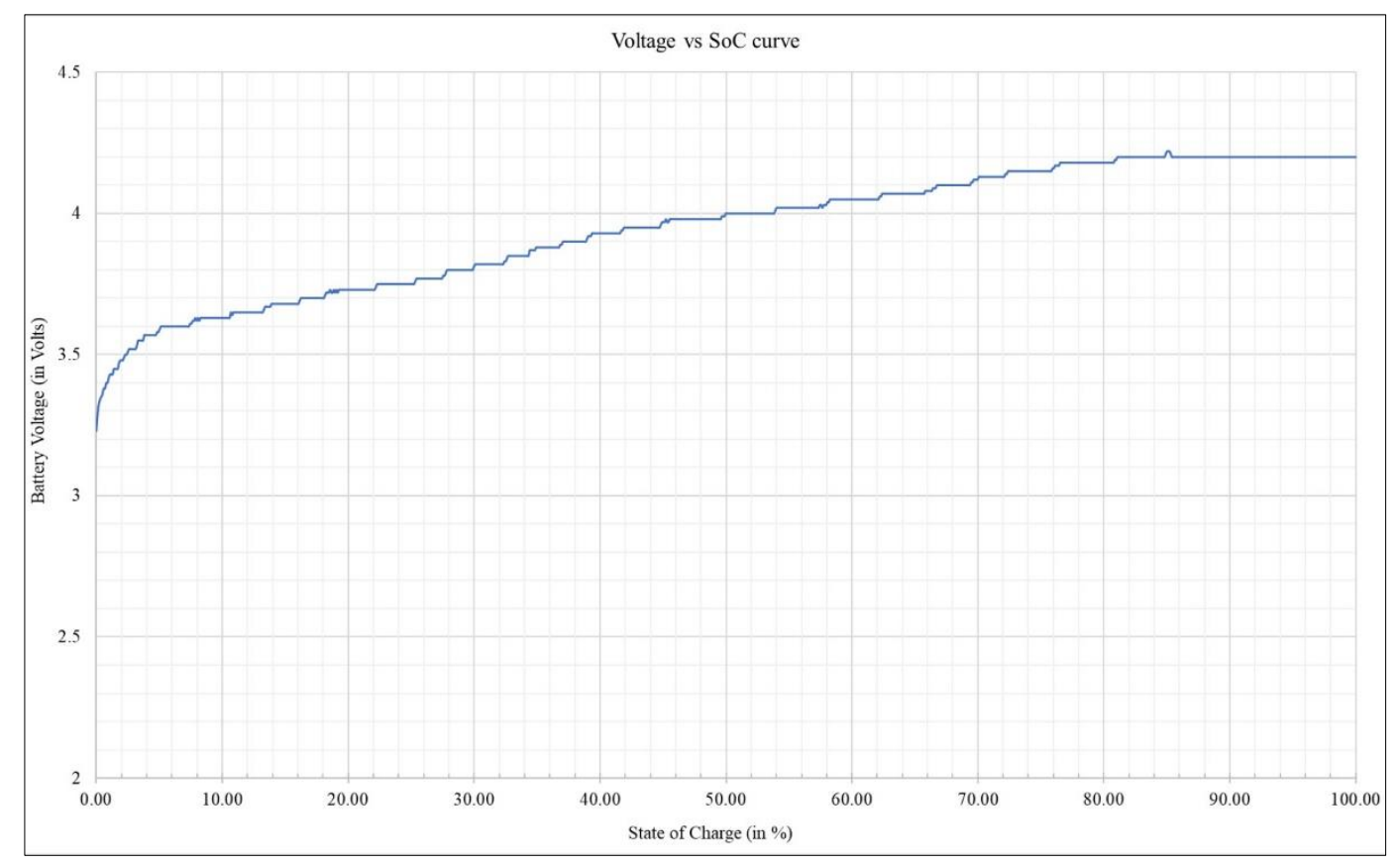

Figure 11 Voltage curve at 1.0A charging rate

However, when the battery was charged with a reference current of $1.5 \mathrm{~A}$, during CC mode of the CC CV charging process, the transition took place at an SoC of $85.02 \%$ and the charging time was 8,275 seconds or $2 \mathrm{hr} 17 \mathrm{mins}$. During this process, it was charged up to $1976 \mathrm{mAh}$ capacity on average.

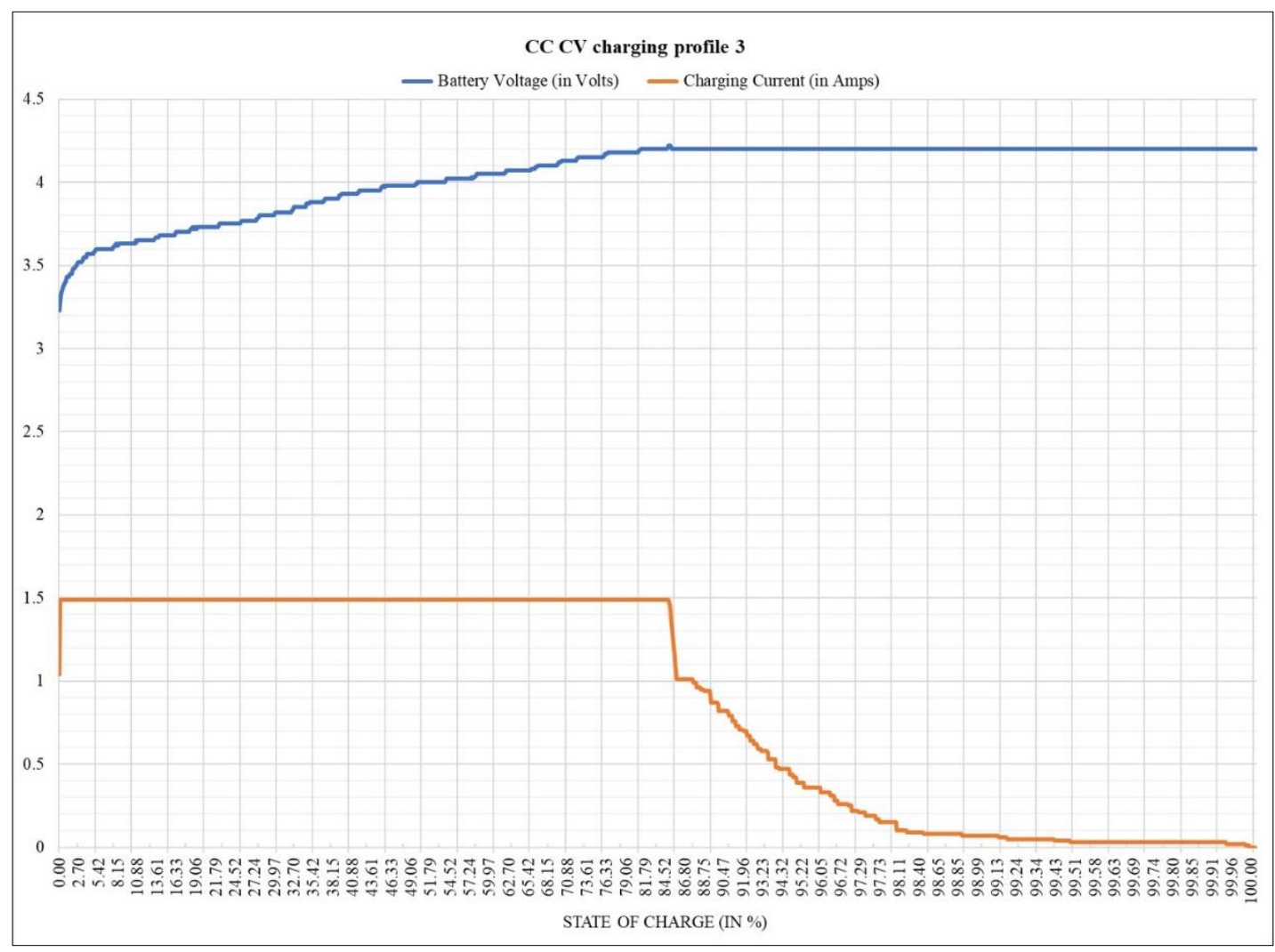

Figure 12 Charging profile with $1.5 \mathrm{~A}$ charging rate

In tests 1,2 and 3, the 18650 battery was charged from $3.21 \mathrm{~V}$ to $4.20 \mathrm{~V}$ in CC CV charging method at $0.85 \mathrm{~A}, 1.0 \mathrm{~A}$ and $1.5 \mathrm{~A}$ respectively. For the purpose of the tests, it was assumed that the battery SoC was 0 at a battery voltage of $3.2 \mathrm{~V}$ 
and is fully charged after it reached $4.2 \mathrm{~V}$ and the current dropped significantly to almost a $0 \mathrm{~A}$ when the process was terminated. This helped us to get an idea about the useable SoC of the battery.

It was found that as the rate of charging increased, the process reached the transition point faster. It was very clearly shown in the figures 7 to 12 . Hence, it can be concluded that the charging mode need to be switched from constant current to constant voltage mode, at a lesser SoC if the rate of charging is high. This result was again similar to the study in [16].

Another observation can be made considering $2197 \mathrm{mAh}$ as the maximum battery capacity. The SoC calculation showed that during the $1.0 \mathrm{~A}$ and $1.5 \mathrm{~A}$ charge cycles, the battery could only be charged up to $2062 \mathrm{mAh}$ and $1976 \mathrm{mAh}$ capacity respectively. This was lesser than the maximum capacity that was calculated only a couple of charge cycles earlier. So, it is unlikely that the battery capacity degraded over such a short period of time. Therefore, the only reason behind that is that when the battery is charged at a higher rate, it is in an over excited state chemically. This offers more resistance to charging and hence it stops charging earlier than it should be, and hence resulting in a partly charged battery. According to the tests conducted, it is reduced by almost $6.14 \%$ and $10.5 \%$ of the maximum capacity for $1.0 \mathrm{~A}$ and $1.5 \mathrm{~A}$ charge cycles respectively. Tests were also conducted at $0.5 \mathrm{~A}$ charging rate as shown in figure 13 , but its results were very similar to that of the $0.85 \mathrm{~A}$ charging except that it took much longer time which is not practical and hence wasn't included in test results.

The ratio of the energy transferred during CC mode to that of CV mode, varies significantly with charging rate. This is consistent with the studies in [9]. From the results of the experiments, it was found that the energy transfer ratio between CC and CV was 42,478:1000,12,586:1000 and 5,675:1000 in tests 1, 2 and 3 respectively.

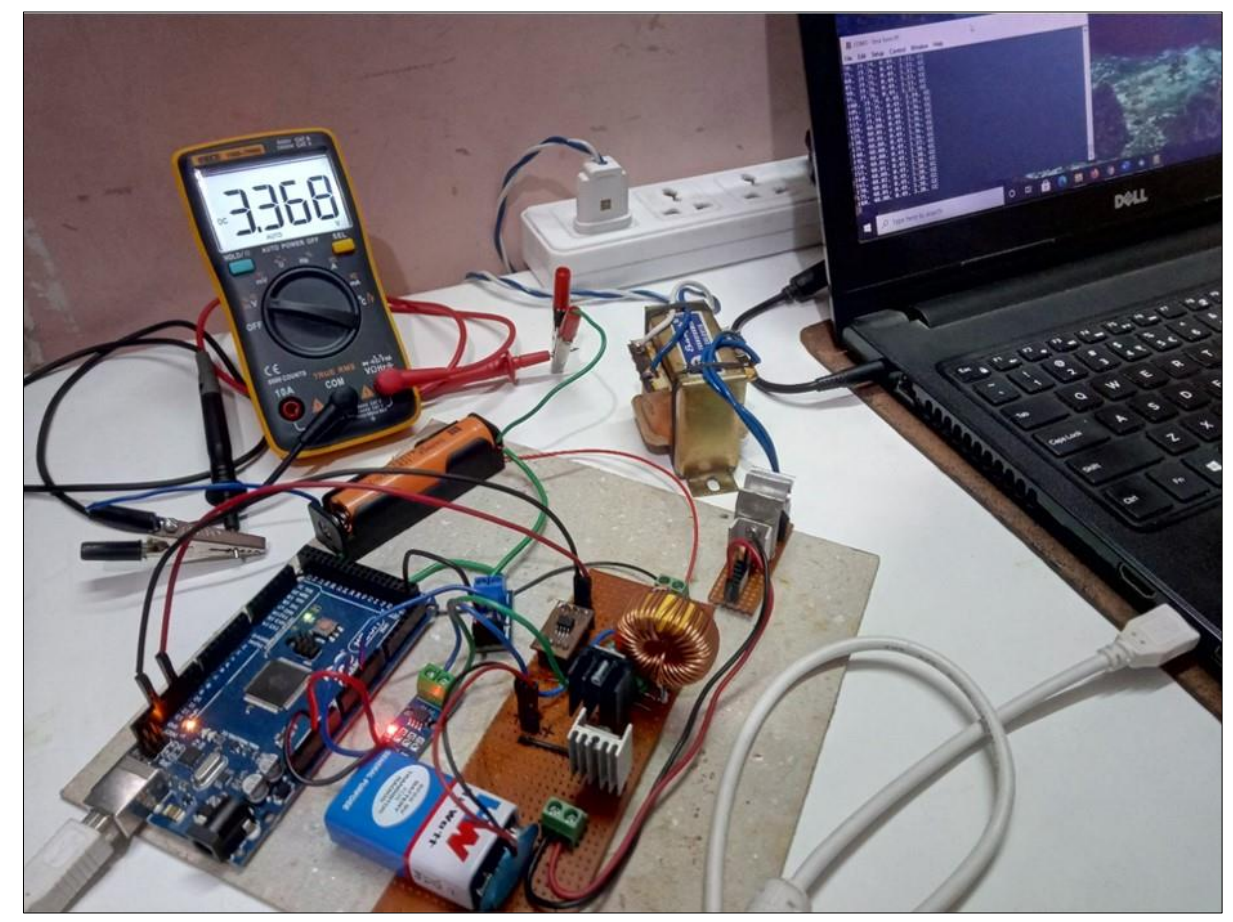

Figure 13 Overall hardware set-up during data logging process during one of the tests at 0.5A

This is alarming as it indicates that if the battery is charged in this process at a faster rate to save time, it actually ends up with a battery that isn't fully charged and will be running short with only $90 \%$ of the useable battery capacity.

Another observation that validates the over excited state when charged at a higher rate is that, after the battery was disconnected from the circuit and allowed a relaxation period of about 4 to 5 hours, the battery voltage dropped slightly from $4.2 \mathrm{~V}$ to $4.17 \mathrm{~V}$. In case of the slower charging rates, even after the relaxation period, the battery voltage remained almost constant with a maximum drop in voltage of about $0.01 \mathrm{~V}$ which is further indication of a stable battery. 
Finally, as the useable capacity of the battery gets recharged, the tests also show that the transition point helps in identifying as the age of the battery as an older battery will have the transition much earlier compared to a newer one due to degradation in capacity when charged at the same rate of charging.

\section{Conclusion}

In this paper, the transition point in the charging point was detected and several important trends of a Li ion battery charging process were observed. It was shown how the transition of charging mode from constant current to constant voltage was accelerated by the charging current rate. It also highlighted important implications with regard to the reliability of the system as it helped to achieve a more accurate estimation of the state of charge of the battery. A slower transition also meant that most of the energy transfer to the battery during the charging process was done at CC mode and very little at CV mode and it gave a much more reliable estimate of the State of Charge. The faster transition also highlighted an apparent degradation in useable battery capacity. The reason it is called apparent is because with a relaxation period of a few hours it can be charge fully again properly. Thanks to the analysis of the test results, new and more efficient mode of charging can be proposed which can be slight modifications to the CC CV charging technique but with a much greater efficiency.

\section{Compliance with ethical standards}

\section{Acknowledgments}

Conveying immense gratitude and thanks to the almighty and the faculty of the department of Power Electronics, Birla Institute of Technology, for the guidance and support without which, this project wouldn't be completed. The topic of this internal research is "Establishment of transition point in operating mode for Constant Current Constant Voltage (CC-CV) charging of Li-ion batteries". The author is open to any ideas or constructive criticism, contributing to the improvement of this project. Hopefully this study will be beneficial to the readers. Thank you.

\section{Disclosure of conflict of interest}

All authors declare that they have no conflict of interest.

\section{References}

[1] Sadeghi-Barzani P, Rajabi-Ghahnavieh A, Kazemi-Karegar H. Optimal fast charging station placing and sizing. Applied Energy. 2014 Jul 15;125:289-99.

[2] Gampa SR, Jasthi K, Goli P, Das D, Bansal RC. Grasshopper optimization algorithm based two stage fuzzy multiobjective approach for optimum sizing and placement of distributed generations, shunt capacitors and electric vehicle charging stations. Journal of Energy Storage. 2020 Feb 1;27:101117.

[3] Bayram IS, Michailidis G, Devetsikiotis M, Bhattacharya S, Chakrabortty A, Granelli F. Local energy storage sizing in plug-in hybrid electric vehicle charging stations under blocking probability constraints. In2011 IEEE International Conference on Smart Grid Communications (SmartGridComm) 2011 Oct 17 (pp. 78-83). IEEE.

[4] McShane EJ, Colclasure AM, Brown DE, Konz ZM, Smith K, McCloskey BD. Quantification of Inactive Lithium and Solid-Electrolyte Interphase Species on Graphite Electrodes after Fast Charging. ACS Energy Letters. 2020 May 21;5(6):2045-51.

[5] Chombo PV, Laoonual Y. A review of safety strategies of a Li-ion battery. Journal of Power Sources. 2020 Dec $1 ; 478: 228649$.

[6] Ouyang D, Chen M, Liu J, Wei R, Weng J, Wang J. Investigation of a commercial lithium-ion battery under overcharge/over-discharge failure conditions. RSC advances. 2018;8(58):33414-24.

[7] Panse K, Dheenadhayalan P, Baby S. A Novel Method of Charging Strategy Optimization Using Evolutionary Algorithm in Battery Electric Vehicles. SAE Technical Paper; 2020 Apr 14.

[8] Nambisan P, Saha P, Khanra M. Real-time optimal fast charging of Li-ion batteries with varying temperature and charging behaviour constraints. Journal of Energy Storage. 2021 Sep 1;41:102918.

[9] Zhang SS. The effect of the charging protocol on the cycle life of a Li-ion battery. Journal of power sources. 2006 Oct 27;161(2):1385-91. 
[10] Notten P, Bergveld H, Kruijt W. Battery management systems: design by modeling.

[11] Willenberg L, Dechent P, Fuchs G, Teuber M, Eckert M, Graff M, Kürten N, Sauer DU, Figgemeier E. The development of jelly roll deformation in 18650 lithium-ion batteries at low state of charge. Journal of The Electrochemical Society. 2020 Aug 6;167(12):120502.

[12] Preger Y, Barkholtz HM, Fresquez A, Campbell DL, Juba BW, Romàn-Kustas J, Ferreira SR, Chalamala B. Degradation of commercial lithium-ion cells as a function of chemistry and cycling conditions. Journal of The Electrochemical Society. 2020 Sep 2;167(12):120532.

[13] Lu W, Zhang L, Qin Y, Jansen A. Calendar and cycle life of lithium-ion batteries containing silicon monoxide anode. Journal of the Electrochemical Society. 2018 Jul 14;165(10):A2179.

[14] Li W, Liu X, Xie Q, You Y, Chi M, Manthiram A. Long-term cyclability of NCM-811 at high voltages in lithium-ion batteries: An in-depth diagnostic study. Chemistry of Materials. 2020 Aug 27;32(18):7796-804.

[15] Abousleiman R, Al-Refai A, Rawashdeh O. Charge capacity versus charge time in CC-CV and pulse charging of Liion batteries. SAE Technical Paper; 2013 Apr 8.

[16] Pavković D, Hrgetić M, Komljenović A, Smetko V. Battery current and voltage control system design with charging application. In2014 IEEE Conference on Control Applications (CCA) 2014 Oct 8 (pp. 1133-1138). IEEE. 